\title{
Is the diversity of the Beach Flies adequately known? Some reflections on the state of the art of current knowledge (Diptera: Canacidae)
}

\begin{abstract}
Riassunto: La diversità delle Beach Flies é adeguatamente conosciuta? Alcune riflessioni sullo stato dell'arte delle attuali conoscenze (Diptera: Canacidae).

Viene fornita una panoramica delle maggiori lacune zoogeografiche nella conoscenza dei canacidi appartenenti alle sottofamiglie Apetaeninae, Horaismopterinae, Pelomyiinae e Tethininae (tutte conosciute come Beach Flies). Le aree identificate trattate in questo lavoro sono le seguenti: la subartica Beringia, le isole circum-antartiche del Sudamerica, la Regione Neotropicale a sud dell'equatore, la maggior parte delle coste marine dell'Africa occidentale, l'immensa area che va dall'India, attraverso il Golfo del Bengala, alle isole di Sumatra e Giava, nonché gran parte dell'Australia. Ad eccezione delle zone inospitali più settentrionali e più meridionali del pianeta, che sono caratterizzate da una reale biodiversità assai scarsa, le restanti vaste aree trattate in questo lavoro soffrono dolorosamente di una drammatica scarsità di raccolte sul campo, come pure di materiali raccolti nel passato e conservati in istituzioni scientifiche. Ciò potrebbe sembrare un'ovvietà che, pur tuttavia, deve essere enfatizzata allo scopo di identificare in maniera inequivocabile le aree geografiche che richiedono di essere ulteriormente indagate. Alla fine della trattazione viene fornita la distribuzione mondiale di tutte le specie citate nel lavoro.
\end{abstract}

\begin{abstract}
An overview of the major zoogeographical gaps in our knowledge of the world beach flies (subfamilies Apetaeninae, Horaismopterinae, Pelomyiinae, and Tethininae) is provided. The identified areas treated in this work are as follows: the subarctic Beringia, the South American circum-Antarctic islands, the Neotropical Region south of the equator, most of the West African seacoasts, the huge area ranging from India, across the Bay of Bengal, to Sumatra and Java, and most of Australia. Apart from the inhospitable northernmost and southernmost areas of the planet, which feature a real very low biodiversity, the remaining vast areas dealt with in this work woefully suffer a dramatic paucity of field collections, as well as of previously collected materials preserved in scientific institutions. This might seem a truism that, however, must be emphasized in order to unequivocally identify the geographic areas that need to be further investigated. At the end of the discussion, the world distribution for all species mentioned in the work is also provided.
\end{abstract}

Key words: Diptera, Canacidae, Beach flies, Biodiversity, Geographical gaps in knowledge.

\section{INTRODUCTION}

"[...] a relatively large proportion of the species in the order Diptera remains undiscovered, unnamed or unidentifiable. This is perhaps in part because of the natural attraction of insect enthusiasts to shining beetles and colorful moths, and perhaps in part because so many groups of flies are relatively small and soft-bodied, and thus more difficult to preserve and study. Up until very recently the study of most groups of flies was also rendered more challenging by a dearth of accessible literature"

Marshall (2012)

True flies of the family Canacidae occur in cool-temperate and tropical zones of the world, primarily on or near seashores with oceanic climates. A few species are found inland, usually in saline or alkaline environments, but occasionally in meadow-like habitats (subfamily Pelomyiinae) or secondarily settled and speciated in freshwater streams of Hawaii (some species of Canacinae). The subfamily Apetaeninae is endemic in the subantarctic archipelagos. Worldwide there are 318 or so species in the family ( 6 subfamilies, 27 genera).

The vernacular group name "Beach Flies" (although some species do not inhabit beaches), as defined in this work, applies to the canacid flies belonging to the former family Tethinidae, which is included now in the family Canacidae sensu lato (the older family-group name; see McAlpine, 2007). This common (or vernacular) name applies only to the following subfamilies: Apetaeninae, Horaismopterinae,

"Lorenzo Munari, c/o Entomology Section, Natural History Museum, S. Croce 1730, 30135 Venezia, Italy. E-mail: munari.lorenzo@gmail.com 
Pelomyiinae (the species of this subfamily are not confined to marine littoral habitats), and Tethininae. The vernacular group names of the other two subfamilies of the Canacidae, i.e. Canacinae and Zaleinae, are "Surf Flies" and "Surge Flies", respectively. The latter vernacular name was recently coined by McAlpine (2007) for the subfamily Zaleinae, whereas the name "Surf Flies" can be found in both the past (e.g. Wirth, 1956) and recent (Mathis, 2010) literature dealing with the Canacidae s.str., which was recently downgraded as subfamily Canacinae (McAlpine, 2007; Munari and Mathis, 2010). Further, we can also find all of the three common names in Marshall's (2012: 373) monograph of the order Diptera, as well as in Munari and Mathis' (in preparation) family chapter of the Manual of Afrotropical Diptera. McAlpine (2007) stated that "such vernacular group names, if consistently applied, can be useful in communicating with non-specialists and non-entomologists, especially those concerned with research funding and conservation ecology".

After studying and describing new genera and numerous new species of beach flies from around the world for thirty-five years, I was asked by some entomologist colleagues whether these flies have therefore been adequately investigated in the major regions of the world, or if there are yet some large geographical gaps to be filled. Indeed, many entomologists still believe that these flies are very poorly represented, their biodiversity being rather poor in species. But, I think this is a false perception. In this regard, I will try here to answer these issues. The total number of world species belonging to the subfamilies regarded here as true beach flies currently amounts to 176 or so. Therefore, if on one hand these canacids certainly cannot be considered as a particularly species-rich group of flies, but at most a taxonomic assemblage showing a fairly low biodiversity, on the other hand these flies have always been woefully neglected by taxonomists in the past, and immense geographical areas of the planet (Fig. 1) are at present very poorly, or not at all, known as to the beach fly fauna (and Diptera in general). Conversely, some geographical areas such as the Euro-Mediterranean subregion, the Nearctic Region, the Gulf of Mexico and the Caribbean, Japan, the subantarctic islands of South Africa and New Zealand, have been adequately inves-

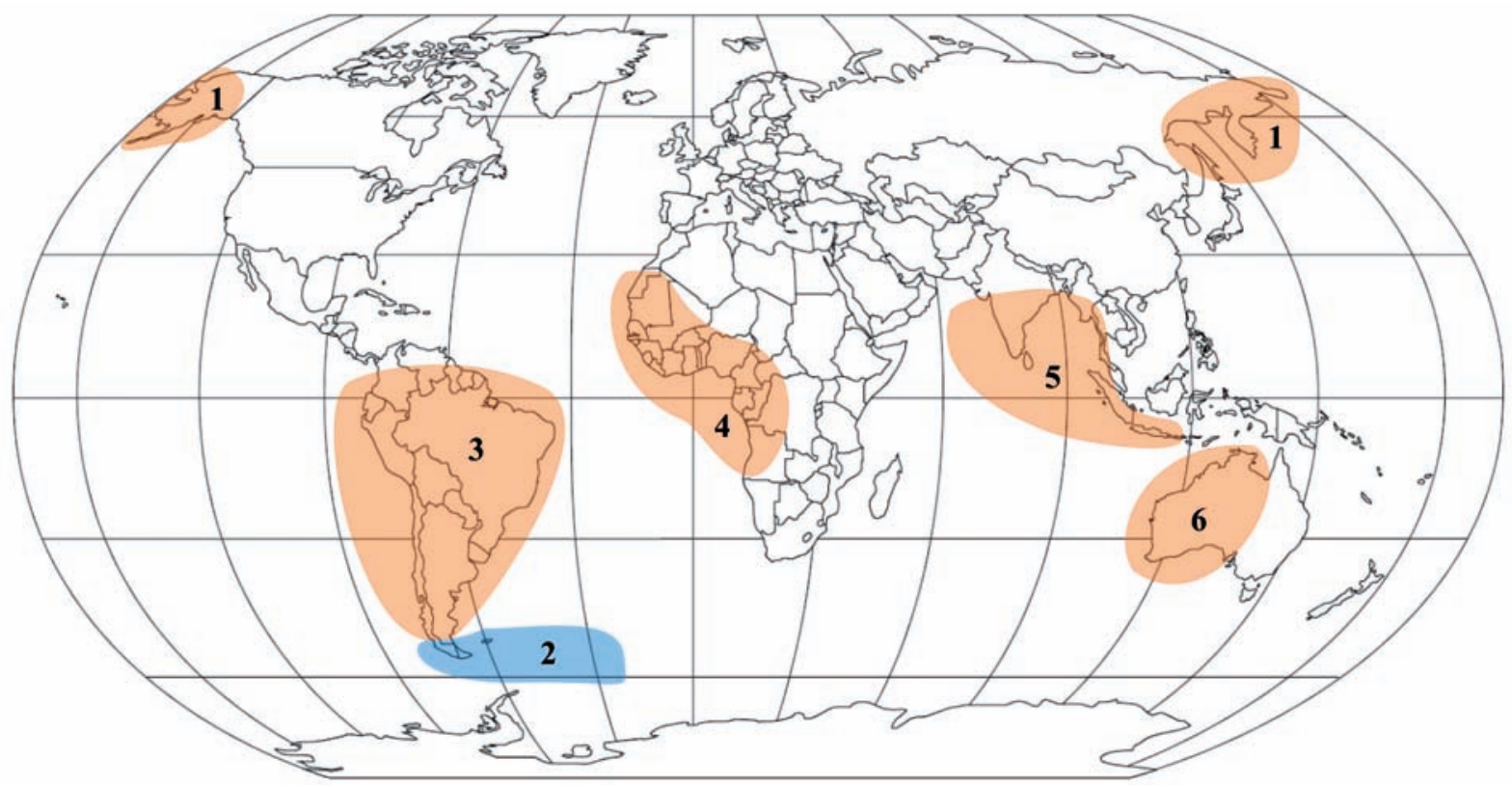

Fig. 1. Planisphere indicating the major hiatuses (areas in colour) of the beach fly spatial distribution in the world. The different colour of the South American subantarctic area indicates the complete lack of beach fly records, especially those relating to the subfamily Apetaeninae. The numbering of the areas in colour refers to the respective sections of the text. 
tigated (although new species are still occasionally described); other areas, such as the eastern seacoasts of the Oriental and Afrotropical Regions, as well as those of eastern Australia, are fairly well known, although many new species are expected to be found in the future. The diverse, remote archipelagos of Oceania (Melanesia, Polynesia and Micronesia) represent another immense oceanic region where the beach fly fauna has been widely investigated in several publications, especially by Munari and by Sasakawa (for details, see Munari and Mathis, 2010). Lastly, the beach flies of the remote Hawaiian Islands were dealt with mainly by Hardy and Delfinado (1980) and by Munari and Evenhuis (2011). No endemic species was found so far in such islands.

This work deals almost exclusively with the maritime environments, leaving out all those geographical zones with continental, eremic or suberemic, saline habitats, which are, for the most part, almost completely unknown. In this connection, as concerns the beach fly fauna from some continental habitats of Central Asia and North Africa-Middle East, the reader is referred to Beschovski and Nartshuk (1997) and Munari (2005a), respectively.

\section{The BEACH FLy DIVERSity: MAJOR GEOGRAPHICAL HIATUSES IN OUR KNOWLEDGE}

1. The Beringian hiatus. The Beringian region, or Beringia, is intended here in its southernmost area, but widened to include a larger area ranging from the Sea of Okhotsk (Russian Far East), through the Bering Sea, to southern Alaska. Only two species of beach flies have been recorded so far from this huge area, Pelomyiella mallochi (Sturtevant, 1923) from Alaska (United States) and Tethina thula Sasakawa, 1986 from Alaska, as well as from Chishima Islands (Sasakawa, 2014) and Hokkaido (both in northern Japan). The latter two Japanese areas are bathed by the southernmost waters of the Sea of Okhotsk. For most of the above citations, see the references in Munari and Mathis (2010). As for the paucity of biodiversity data for the beach flies inhabiting other high-latitudes areas, we can find an emblematic evidence in Kahanpää's (2014) checklist dealing with some acalyptrate families from Finland. In this work, the Finnish author did not cite any species of Tethininae from Finland, excluding the only two species, i.e Tethina grisea (Fallén, 1823) and T. illota (Haliday, 1838), previously reported from the literature by Munari and Mathis (2010). Indeed, Ka- hanpää (2014) regarded the occurrence of these two species in Finland as very doubtful. However, a pelomyiine species (subfamily Pelomyiinae), Pelomyiella cinerella (Haliday, 1837), is known from Finland (Munari and Mathis, 2010; Kahanpää, 2014). Furthermore, Munari (2011) also recorded an additional species of pelomyiine fly, Pelomyiella mallochi (Sturtevant, 1923), from the Russian Arctic territories (Yamal Peninsula, $70^{\circ} 11^{\prime} \mathrm{N}-67^{\circ} 17^{\prime} \mathrm{E}$ ). Apart from Alaska and the above-mentioned Russian record, this very common and widely distributed species is also known at high-latitudes from the Northwest Territories of Canada and from Greenland (Munari and Mathis, 2010). Therefore, we can affirm, with a reasonable reliability, that the beach fly fauna from high-latitudes territories is very poorly represented, even though it has been scarcely investigated. Thus, the Beringian hiatus is probably only apparent, due to the often extreme living conditions in this cold, subarctic region.

2. The South American subantartic hiatus: the SUBANTARCTIC ISLANDS OF SOUTH AMERICA (INCLUDING TierRA DEL Fuego AND FALKLANDS) AND OF THE SOUTHern Atlantic Ocean. Apart from one species of Pelomyiinae, Pelomyia fuegina Munari, 2010, described from Tierra del Fuego and known only from the type locality (Estancia Viamonte, Auricosta), no other species of beach flies, especially the subantarctic endemic subfamily Apetaeninae, is recorded from this southernmost, extreme oceanic area. As for this subfamily, Munari (2008) stated that "[...] although we know these flies exhaustively from both the Kerguelen Biogeographical Province and New Zealand-Australian subantarctic islands, no species is known so far from the subantarctic territories of South America [...], viz. Southern Patagonia (including Tierra del Fuego Island), Falklands, South Georgia, South Sandwich, Austral Shetland, South Orkney islands, and the easternmost, oceanic Bouvet Island (Bouvetøia)". In the same paper the author also says that "Since many of these islands are overseas British possessions, I hopefully supposed that a number of specimens could be found in the collection of the Natural History Museum, London, as a result of British, subantarctic, entomological expeditions carried out in the past". Nevertheless, the curator of Diptera of that museum informed that no specimens of Apetaeninae from the subantarctic lands of South America had been found in the collection of the London museum. The same kind of negative answer was also 
given by the curator of the Diptera collection at the Smithsonian National Museum of Natural History, Washington. No doubt, there is a reasonable expectation to find these flies from those cold, windy, rocky seacoasts. This is because the latitudinal, climatic, and environmental characteristics of those mostly inhospitable oceanic places north of $60^{\circ} \mathrm{S}$ (except for the South Orkney Islands which are $60^{\circ} 35^{\prime} \mathrm{S}$ ) are, to a large extent, the same as in all other circum-Antarctic islands, where, on the contrary, the apetaenine flies are well represented (Fig. 2) (Munari, 2007; 2008). Thus, the low biodiversity occurring in the subantarctic islands gives no apparent reason for accounting for the absence of the apetaenine flies in the subantarctic insular lands of South America. On the other hand, it is also true that an ecologically very similar and commonly recorded family of seaweed flies, Coelopidae, is strangely absent from the wrack-rich coasts of southern South America, where it seems to be replaced by superficially similar flies in the related family Helcomyzidae (Marshall, 2012). Indeed, the helcomyzid genus Paractora Bigot, 1888 , occurs mostly in southern South America, where its species seem to replace Coelopidae as the dominant large wrack flies (Marshall, 2012). In those circumstances, it is not unlikely that even the apetaenine flies have been replaced in those lands by more competitive large wrack flies. However, to disprove this, at least in part, Crafford et al. (1986) state that, in the Kerguelen Province, dense aggregates of adults of Apetaenus litoralis Eaton, 1875 (Canacidae, Apetaeninae) may be found sheltering with adults of Paractora dreuxi mirabilis Séguy, 1971 (Helcomyzidae) amongst fronds of stranded Durvillaea antarctica (Chamisso) Hariot (Durvillaeales). Munari $(2007 ; 2008)$ provides a great number of detailed remarks about the habitats and the microhabitats of the Apetaeninae and other seaweed flies from the Kerguelen province, as well as from the subantarctic islands of New Zealand. In conclusion, we can say that the absence of the apetaenine flies in the sub-antarctic South America still remains an unresolved issue. It is hoped that this hiatus will be filled when specialized fly collections are targeted on those islands (also see the "conclusions" at the end of this work).

Number and distribution of the apetenine species/subspecies in the Circum-Antarctic belt:

i) Subantarctic islands of South America: 0

ii) Subantarctic islands of South Africa (Kerguelen Province): 3

iii) Subantarctic islands of New Zealand: 3
No species/subspecies occurs in the same subantarctic provinces.

\section{The South American hiatus: the Neotropical} REGION SOUTH OF THE EQUATOR. This is an immense zoogeographical region with thousands of kilometres of coastal environments mostly ranging from north to south and bathed by the waters of the Atlantic (East Coast) and Pacific (West Coast) Oceans. The beach flies are represented by the genera Pelomyia Williston, 1893, Masoniella Vockeroth, (1987, published as nomen nudum) 1995 (validation), Dasyrhicnoessa Hendel, 1934 (occurring with one species only), and Tethina Haliday, 1837.

Far from being exhaustively represented, nevertheless the subfamily Pelomyiinae is fairly well known in this huge region, especially thanks to Foster and Mathis' (2003) revision of the only two genera occurring in South America, namely Pelomyia and $\mathrm{Ma}$ -

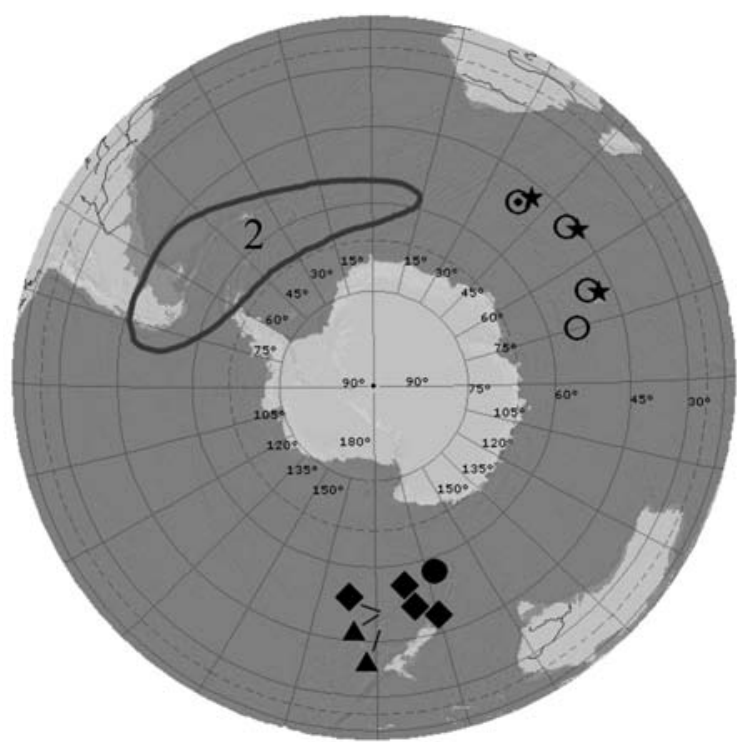

Fig. 2. Distributional map of the subfamily Apetaeninae (as for the insular toponyms, see the distributions given in $\mathrm{Mu}-$ nari, 2007, 2008). Slightly modified after Munari, 2008. Legend: geographical area delimited by a thick grey line (section 2 of the text)=zoogeographical gap (no species has been recorded so far); $\bigcirc=A$. (Apetaenus) litoralis litoralis Eaton; $\odot=A$. (Apetaenus) litoralis marionensis Munari; $\bullet=A$. (Apetaenus) litoralis watsoni Hardy; $\star=A$. (Listriomastax) enderleini Munari; $\diamond=A$. (Macrocanace) australis (Hutton); $\boldsymbol{\Delta}=$ A. (Macrocanace) littoreus (Hutton). 
soniella. In that revision, Foster and Mathis recorded all species from the previous literature and described 5 new species of Masoniella and 22 of Pelomyia from the Neotropical Region. Munari $(2010 ; 2013)$ also described a few additional new species of pelomyiine flies from this region [for a detailed list of species, the reader is referred to Foster and Mathis'(2003) and Munari's $(2010 ; 2013)$ papers]. As concerns the subfamily Tethininae, the Galápagos archipelago represents a fairly investigated area (Foster and Mathis, 2008), with three species of Tethina recorded so far, i.e. T. albula (Loew, 1869), T. insulans Curran, 1932, and T. spinulosa Cole, 1923. Except for these two abovementioned cases, very little is known about the diversity of the Tethininae inhabiting South America south of the equator. The fauna of these flies from the western (Pacific) continental seacoast is very poorly known, with only six species of Tethina, mostly recorded from Chile (see further), i.e. T. albitarsa Foster and Mathis, 1998, T. albula (Loew, 1869), T. pallipes (described by Malloch (1934) from Chile as $T$. chilensis, a junior synonym), T. robusta Foster and Mathis, 2000, T. spinulosa, and T. willistoni (Melander, 1913). An even worse situation occurs for the tethinine species of the Atlantic seacoast. Only one species of Dasyrhicnoessa, D. insularis (Aldrich, 1931), and four species of Tethina, namely T. albula, T. brasiliensis Prado and Tavares, 1966, T. willistoni, and T. xanthopoda (Williston, 1896), have been recorded so far from this immense area. From a zoogeographical point of view, the taxonomic affinities for the tethinine species are exclusively towards the north (excepting Dasyrhicnoessa insularis, which is a very common pantropical species), specifically to the Nearctic Region, whereas the pelomyiine species have, to a large extent, their centre of dispersion just in the vast area treated here. The beach fly fauna of this area necessarily needs a lot of field collections in diversified saline habitats, especially those in proximity to the seacoast (including mangrove swamps). Indeed, numerous undescribed species will be expected to be found on both the Pacific and Atlantic seacoasts of this continent.

Number and distribution of the Beach Fly species recorded in the New World:

i) Nearctic Region: 29

ii) Neotropical Region (including Central America and South America north of the Equator): 42

Eight species occur in both the Regions.
4. The West African hiatus (from Angola to WeStERn SAHARA). The area treated herein intentionally excludes the countries of Namibia (to the south) and Morocco (to the north). As to the beach fly fauna, the former country was exhaustively investigated (though dealing exclusively with the intertidal habitats of the seacoast) especially by Kirk-Spriggs et al. (2001), but other additional citations can be found in Munari and Mathis' (2010) world catalogue of the family. For the species of Morocco, the reader is referred to the citations in the latter publication. Differently from the fairly well-known fauna of the East African seacoast, that inhabiting the seashores of West Africa has woefully been poorly investigated. Although with some misidentifications (for details see Munari and Baez, 2000), Frey (1958) published a paper dealing with the Diptera of the Cape Verde Islands. Cogan's (1980) catalogue of Afrotropical Diptera also reported those misidentifications uncritically. In these outdated publications, which were the most complete references available at that time, an undescribed species, i.e. Tethina amphitrite Munari and Baez, 2000, was misidentified with the common $T$. incisuralis (Macquart, 1851), which has never correctly been recorded from the Cape Verde Islands. The confusion between the two species arose in that $T$. amphitrite is very similar externally to Macquart's species, and both the species share the same kind of maritime habitat. Vanschuytbroeck (1976) reported $T$. alboguttata (Strobl, 1900) from the remote, oceanic island of St. Helena in the southern Atlantic Ocean. The identifications made by Vanschuytbroeck were partly confirmed by Munari (1994), who examined a single female specimen. However, a second male specimen from the same locality remained undetermined because of its poor condition of preservation (Munari, 1994). Excepting the above-mentioned records, only very few additional species were reported in the literature of those years (Cogan, 1980). Later, some other species were also recorded or newly described from the continental seacoast of western Africa (detailed references are in Munari and Mathis, 2010): Afrotethina kaplanae Munari, 1994 (from Cameroon and Sierra Leone), Dasyrhicnoessa insularis (from Cameroon, Nigeria, and Sierra Leone), Tethina albosetulosa (Strobl, 1900) (from Senegal), T. soikai Munari, 1981a (from the Cape Verde Islands and Senegal). Two other species, namely $T$. grossipes (Becker, 1908) (from the Cape Verde Islands) and $T$. 
pallipes (from the Cape Verde Islands and Senegal), were also recorded by Cogan (1980) from the islands of Cape Verde.

Apart from the four citations from the Cape Verde Islands, we can realize the extreme shortage of field collections throughout this immense area ranging from the southernmost boundaries of Angola to the northernmost ones of Western Sahara. Furthermore, we do not know if a few species of the afrotropical genus Horaismoptera Hendel, 1907 (subfamily Horaismopterinae) inhabit the beaches of western Africa north of Namibia, as the westernmost records of this afrotropical genus are from the latter country and refer to H. microphthalma (Bezzi, 1908). This species was described from Namibia (Lüderitz Bay) and subsequently reported from the same country by KirkSpriggs et al. (2001) and by Munari (2009) (Fig. 3). H. microphthalma occurs mainly on rocky and sandy beaches, where abundant kelp heaps and marine debris have been washed up by the waves. Also, KirkSpriggs et al. (2001) recorded from Namibia some species of another endemic afrotropical genus, i.e. Afrotethina Munari, 1986, which is rather common (eight species are known) in southern and eastern Africa, as well as in the Arabian Peninsula. However, in the western beaches (north of Namibia), only one species of this genus, A. kaplanae, is known from Cameroon and Sierra Leone, and no additional species have been recorded so far.

Number and distribution of the Beach Fly species recorded in the Afrotropical Region:

i) West Africa: 11

ii) South and East Africa (excluding Madagascar, but including the small oceanic archipelagos): 25

iii) Madagascar: 6

Number of shared species:

i) West Africa - South and East Africa: 5

ii) West Africa - Madagascar: 1

iii) South and East Africa - Madagascar: 5

5. The Indian hiATUS: FROM India, ACROSS the BAY of Bengal, to Sumatra AND Java. Along with most of Australia (see further), this is one of the most poorly investigated huge areas of the world (at least as far as the beach flies are concerned). Only seven species of these flies have been recorded inhabiting this immense territory ranging from the western seacoast of India to Java, four of them being known from the large island of Sri Lanka, i.e. Horaismoptera hennigi Sabrosky,
1978, Dasyrhicnoessa fulva (Hendel, 1913), Dasyrhicnoessa vockerothi Hardy and Delfinado, 1980, and Pseudorhicnoessa rattii Munari, 1981b. Especially noteworthy is the first species, which belongs to an afrotropical genus and is, in all probability, a vicariant species of an ancestral lineage, whose extant species still inhabit the seacoasts of Africa and the Arabian Peninsula (Fig. 3). Therefore, its taxonomic affinities are to the west and southwest, and specifically with the eastern and southern afrotropical seashores. Pseudorhicnoessa rattii is also known from western India (state of Goa), in addition to some archipelagos of the western Indian Ocean (see further). This species is the western vicariant of $P$. spinipes Malloch, 1914, the latter widely distributed in the western Pacific Ocean as far as the Sunda Islands. The few remaining species of the Indian hiatus are the following: Dasyrhicnoessa adelpha Munari, 2005, so far exclusively known from West India (state of Goa), the common Pseudorhicnoessa spinipes, with a few records (six specimens in all) from southeastern Thailand (Munari, 2005b), and the subcosmopolitan Tethina pallipes, with an isolated, continental (an inland area over $700 \mathrm{~km}$ from the nearest seacoast) record from India (Munari, 2009). Apart from the two species $\mathrm{Ho}$ raismoptera hennigi and Dasyrhicnoessa adelpha, which are known from the types only, the other species show taxonomic affinities to the east, espe-

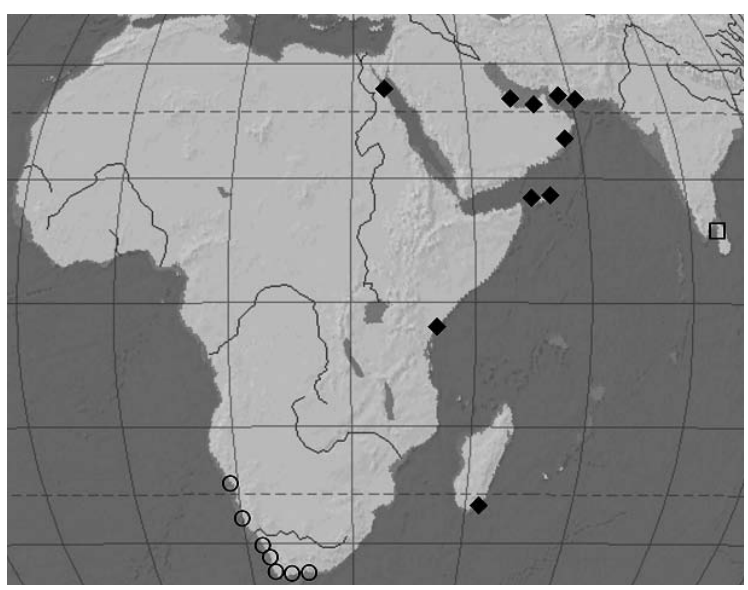

Fig. 3. Distribution map for the species of the genus Horaismoptera Hendel: H. hennigi Sabrosky (open square), H. microphthalma (Bezzi) (open circles), H. vulpina Hendel (diamonds). After Munari, 2009. 
cially with the Indo-Malay and western Pacific areas, excepting Pseudorhicnoessa rattii which exclusively inhabits the beaches of the Indian Ocean.

Similar to many other geographical areas, shortage of field collections and especially the dramatic scarcity of local fly collectors (if any) have caused, as a consequence, an extreme paucity of materials available for study. Given the abundance of mangrove swamps on the seacoasts of this territory, many previously described, or even undescribed, species of Dasyrhicnoessa are therefore expected to be found, they being rather strictly associated with the clay tidal flats in the mangrove environment.

Number and distribution of the Beach Fly species recorded in the Oriental Region:

i) Western Oriental Region (this side is that treated in this work): 8

ii) Eastern Oriental Region: 10

Four species occur in both the western and eastern areas.

The whole Oriental Region dramatically suffers a critical shortage of findings, especially the west side of the Region.

6. The Australian hiatus: North, South, and West Australia. With regard to Australia, our knowledge contains a huge gap, as little is known about the beach flies of the Northern Territory, Western Australia and South Australia. An indication of this is the fairly recent discovery of two new genera and three new species from Western Australia (Munari, 2004), which were segregated from extremely scanty material, as a result of quite occasional field collections. Marshall (2012) stated that "the 19,000 or so species of flies currently known from the Australasian region probably represent considerably less than half of the actual fauna", endemism at the generic and specific level being very high, with many characteristic regional undescribed taxa. Five species are currently known from the Northern Territory, namely Dasyrhicnoessa ciliata Munari, 2004, D. macalpinei Munari, 2004, the common D. vockerothi and Pseudorhicnoessa spinipes, and Sigaloethina phaia Munari, 2004, three of which were recently described (Munari, 2004). Four additional species, including two recently described genera, are known inhabiting the seashores of Western Australia, namely Plesiotethina australis Munari, 2000, Tethina hirsuta Munari, 2000, the common T. pallidiseta Malloch, 1935, and Thitena cadav- erina Munari, 2004. Even worse, no species of beach flies from South Australia has been reported so far in the literature.

The above-mentioned genera Plesiotethina Munari, 2000, Sigaloethina Munari, 2004, and Thitena Munari, 2004 are, in all probability, endemic to Australia, except perhaps for the genus Sigaloethina that could likely occur in Papua New Guinea, too. Plesiotethina is noteworthy for being an enigmatic genus of uncertain placement at the subfamilial level within the former family Tethinidae (beach flies). So far, the most comprehensive papers dealing with the Australian beach fly fauna are those recently published by Munari $(2000 ; 2004)$, in which three new genera and twelve new species were described, especially from the eastern coast of Australia (Munari, 2004), where there are the higher concentration of dipterist specialists as well as the largest dipterological collections housed in important scientific institutions (ANICCSIRO, Canberra) and museums (Sydney).

Number and distribution of the Beach Fly species recorded in Australia:

i) Northern Territory: 5

ii) Western Australia: 5

iii) South Australia: 0

iv) Eastern coast of Australia (from Queensland south to Tasmania): 18

Number of shared species:

i) Northern Territory - Eastern coast: 3

ii) Western Australia - Eastern coast: 1

iii) Northern Territory - Western Australia: 0

\section{CONCLUSIONS}

Like many other families of flies, the scenario shown in the present work features the extreme paucity of past and recent field collections in the examined geographical areas, rather than a very low diversity as concerns the beach flies, which represent worldwide more than $55 \%$ of the overall biodiversity of the entire family Canacidae (that is, including the subfamilies Canacinae (Surf Flies) and Zaleinae (Surge Flies)). This might seem a truism that, however, must be emphasized in order to unequivocally identify the geographic areas that need to be further investigated. In this context, the most dramatic gap in our knowledge is that relating to the South American subantarctic hiatus. It would actually be extremely interesting to know which apetaenine species (if any!) inhabit the subantarctic islands of South America, as 
no record has been reported so far in the literature (see details in the above section dedicated to this area). This would allow us better to understand the phylogenetic relationships that exist between all species of circum-Antarctic apetenine flies (Munari, 2007; 2008). This cold, oceanic, circum-Antarctic belt was revealingly named "Insulantarctica" according to the classification developed by Udvardy (1975). It is a biogeographical province of the Antarctic Biogeographical Realm, which comprises scattered islands of the Southern Ocean showing clear affinity to each other. As for the other huge zoogeographical hiatuses, we can notice the extreme paucity of data for the
Neotropics (south of the equator), West Africa, and the northern and eastern Indian Ocean, including the seacoasts of most of Australia. Several undescribed species are expected to be found in these areas, especially from the Australian seashores, where new genera and species predictably occur.

\section{ACKNOWLEDGEMENTS}

I wish to express my sincerest gratitude to Dr. John Deeming (Cardiff, UK) for critically reviewing the final draft of this work. Particular thanks are also due to my son Emiliano for processing the planisphere shown in Fig. 1.

\section{REFERENCES}

AlDRICH J.M., 1931 - New Acalyptrate Diptera from the Pacific and Oriental Regions. Proceedings of the Hawaiian Entomological Society, 7(3): 395-399.

BECKER T., 1908 - Dipteren der Kanarischen Inseln. Mitteilungen aus dem Zoologischen Museum in Berlin, 4(1): 1-180.

BESCHOVSKI V.L., NARTSHUK E.P., 1997 - The Tethinidae species in the collection of the Zoological Institute in St. Petersburg (Insecta: Diptera: Tethinidae). Reichenbachia, 32(22): 129-141.

Bigot J.M.F., 1888 - Dipteres [sect. v.]. Pp. 1-45, pls. 1-4. In: Ministères de la Marine et de l'Instruction Publique, Mission scientifique du Cap Horn. 1882-1883. Tome VI. Zoologie. Insectes. Gauthier-Villars et Fils, Paris.

Cogan B.H., 1980 - 78 - Family Tethinidae. In: Crosskey R.W., (ed), Catalogue of the Diptera of the Afrotropical Region. British Museum (Natural History). London: page 693.

Cole F.R., 1923 - Expedition of the California Academy of Sciences to the Gulf of California in 1921. Diptera from the Islands and Adjacent Shores of the Gulf of California. II. General Report. Proceedings of the California Academy of Sciences, 12(25): 457-481.

Crafford J.E., Scholtz C.H., Chown S.L., 1986 - The insects of sub-Antarctic Marion and Prince Edward Islands; with a bibliography of Entomology of the Kerguelen Biogeographical Province. South African journal of antarctic research, 16(2): 42-84.

CURRAN C.H., 1932 - The Norwegian Zoological Expedition to the Galapagos Islands 1925, Conducted by Alf Wollebaek. IV. Diptera. (Excl. of Tipulidae and Culicidae). Meddelelser fra det Zoologiske Museum, Oslo, 30: 347-366.

EATON A.E., 1875 - Breves Dipterarum uniusque Lepidopterarum insulae Kerguelensi indigenarum diagnoses. The Entomologist's Monthly Magazine, 12: 58-61.

FALLÉn C.F., 1823 - Agromyzides Sveciae. Berling, Lundae [= Lund], 10 pages.

Foster G.A., Mathis W.N., 1998 - A Revision of the Family Tethinidae (Diptera) from the Caribbean, Gulf of Mexico, and Bermuda. Proceedings of the Entomological Society of Washington, 100(4): 601-632.

Foster G.A., Mathis W.N., 2000 - Notes on Neotropical species of Tethina Haliday (Diptera: Tethinidae). Proceedings of the Entomological Society of Washington, 102(3): 542-548.

Foster G.A., Mathis W.N., 2003 - A revision of the genera Pelomyia Williston and Masoniella Vockeroth (Diptera: Tethinidae). Smithsonian Contributions to Zoology, 619: 1-63.

Foster G.A., Mathis W.N., 2008 - A review of the Tethininae (Diptera: Canacidae) from the Galápagos Islands. Proceedings of the Entomological Society of Washington, 110(3): 743-752.

Frey R., 1958 - Zur Kenntnis der Diptera brachycera p.p. der Kapverdischen Inseln. Commentationes Biologicae, 18(4): 1-61. HaLidaY A.H., 1837 - Notes \& c. upon Diptera. Entomological Magazine, 4(2): 147-152.

HaLidAY A.H., 1838 - New British Insects Indicated in Mr. Curtis's Guide [part]. Annals and Magazine of Natural History, 2: 183-190. 
Hardy D.E., Delfinado M.D., 1980 - Family Tethinidae. In: Hardy D.E., Delfinado M.D., (eds), Insects of Hawaii, 13: 369379. Diptera: Cyclorrhapha III. Honolulu: University Press of Hawaii, 451 pages.

Hendel F., 1913 - Acalyptrate Musciden (Dipt.) II. In: H. Sauter's Formosa-Ausbeute. Supplementa Entomologica, 2: 77-112.

Hendel F., 1934 - Revision der Tethiniden (Dipt. Muscid. acal.). Tijdschrift voor Entomologie, 77: 37-54.

Kahanpä̈̈ J., 2014 - Checklist of the Diptera families Acartophthalmidae, Canacidae (including Tethinidae), Carnidae and Milichiidae of Finland (Insecta). ZooKeys, 441: 305-309.

Kirk-Spriggs A.H., Ismay J.W., Ackland M., Roháček J., Mathis W.N., Foster G.A., Pape T., Cranston P.S., Meier R., 2001 - Inter-tidal Diptera of southwestern Africa (Chironomidae, Canacidae, Chloropidae, Milichiidae, Tethinidae, Ephydridae, Sphaeroceridae, Coelopidae, Sarcophagidae and Anthomyiidae). Cimbebasia, 17: 85-135.

LoEw H., 1865 - Ueber die europäischen Arten der Gattung Rhicnoëssa. Berliner Entomologische Zeitschrift, 9: 34-39.

LoEw H., 1869 - Diptera Americae septentrionalis indigena. Berliner Entomologische Zeitschrift, 13: 1-52.

Malloch J.R., 1914 - Formosan Agromyzidae. Annales Musei Nationalis Hungarici, 12: 306-336.

Malloch J.R., 1934 - Tethinidae. In: Edwards F.W., (ed), Diptera of Patagonia and South Chile, 6(5): 452-460. London: British Museum (Natural History), 393-490 pages.

Malloch J.R., 1935 - Notes on and descriptions of new species of Australian Diptera. Australian Zoologist, 8(2): 87-95.

MARShall S.A., 2012 - Flies: the natural history and diversity of Diptera. Firefly Books Ltd., 616 pages.

Mathis W.N., 2010 - 89. Canacidae (Surf Flies). In: Brown B.V., Borkent A., Cumming J.M., Wood D.M., Woodley N.E., Zumbado M.A., (eds), Manual of Central American Diptera, Volume 2, NRC Research Press, Ottawa, 728 pp. (Canacidae on pages 1115-1119).

MCAlPINE D.K., 2007 - The surge flies (Diptera: Canacidae: Zaleinae) of Australasia and notes on Tethinid-Canacid morphology and relationships. Records of the Australian Museum, 59(1): 27-64.

Melander A.L., 1913 - A synopsis of the dipterous groups Agromyzinae, Milichinae, Ochthiphilinae and Geomyzinae. Journal of the New York Entomological Society, 21(4): 283-300.

MunARi L., 1981a - Tre nuove Tethina Haliday raccolte dal Prof. A. Giordani Soika in Asia minore e Senegal (Diptera, Tethinidae). Bollettino del Museo civico di Storia naturale di Venezia, 31(1980): 139-144.

MunARi L., 1981b - Sul genere Pseudorhicnoessa Malloch, 1914 (Diptera Tethinidae). Società Veneziana di Scienze Naturali Lavori, 6: 91-96.

MunARI L., 1994 - Contribution to the knowledge of Afrotropical Tethinidae. VII. New species and records, with a check-list of Afrotropical species (Diptera, Acalyptratae). Società Veneziana di Scienze Naturali - Lavori, 19: 15-28.

MunARi L., 2000 - Beach Flies from south-western coast of Australia, with descriptions of a new genus and two new species (Diptera Tethinidae). Bollettino della Società Entomologica Italiana, 132(3): 237-248.

Munari L., 2004 - Beach Flies (Diptera: Tethinidae: Tethininae) from Australia and Papua New Guinea, with descriptions of two new genera and ten new species. Records of the Australian Museum, Sydney, 56(1): 29-56.

Munari L., 2005a - Species of Tethina Haliday from the Sahara and inland biotopes of the Mediterranean subregion (Diptera: Tethinidae). Stuttgarter Beiträge zur Naturkunde, Serie A (Biologie), 683: 1-11.

MunARI L., 2005b - Indo-Pacific beach flies (Diptera: Tethinidae): New species and records from the Indian and Western Pacific Oceans. Studia dipterologica, 11(2) (2004): 585-596.

MunARi L., 2007 - Studies on the Canacidae (Diptera), subfamily Apetaeninae. I. Apetaenus enderleini, nomen novum for Listriomastax litorea Enderlein, 1909, with remarks on the chaetotaxy, morphology, and habitats of the Apetaeninae from the Kerguelen Biogeographical Province. Zootaxa, 1542: 21-34.

MunARI L., 2008 - Studies on the Canacidae (Diptera), subfamily Apetaeninae. II. A review of the world subgenera of Apetaenus Eaton, with a special reference to the Australian and New Zealand species. Zootaxa, 1692: 26-42.

MUNARI L., 2009 - New or interesting records of beach flies from the Afrotropical and Oriental Regions (Diptera: Canacidae: Horaismopterinae, Tethininae). Bollettino del Museo civico di Storia naturale di Venezia, 59(2008): 55-59.

MunARi L., 2010 - Canacidae and Australimyzidae (Diptera) collected by Danish Scientific Expeditions and by N.L.H. Krauss, with descriptions of four new species. Steenstrupia, 32(1): 51-68.

MunARi L., 2011 - The Euro-Mediterranean Canacidae s.l. (including Tethinidae): keys and remarks to genera and species (Insecta, Diptera). Bollettino del Museo di Storia Naturale di Venezia, 62: 55-86. 
MunARi L., 2013 - A new species of Pelomyia Williston, 1893 from Chile (Diptera: Canacidae: Pelomyiinae). Società Veneziana di Scienze Naturali - Lavori, 38: 21-26.

MunARI L., BÁEz M., 2000 - The Tethinidae of Macaronesia: a faunal revision, with descriptions of two new species (Diptera). Bollettino del Museo civico di Storia naturale di Venezia, 50(1999): 3-30.

Munari L., Evenhuis N.L., 2011 - The subfamily Tethininae (Diptera: Canacidae) in the Hawaiian Islands. Bishop Museum Occasional Papers, 109: 25-34.

Munari L., Mathis W.N., 2010 - World Catalog of the Family Canacidae (including Tethinidae) (Diptera), with keys to the supraspecific taxa. Zootaxa, 2471: 1-84.

Munari L., Mathis W.N., (in preparation) - 94. Canacidae (Beach Flies, Surf Flies and Surge Flies). In, A. Kirk-Spriggs and M. Mostovski, editors, Manual of Afrotropical Diptera, Vol. 2 [release planned for 2018].

Prado A.P. Do, Tavares O., 1966 - Sôbre duas espécies novas do gênero “Tethina” Haliday, 1838 (Diptera, Tethinidae). Revista Brasileira de Biologia, 26(4) : 429-439.

SABrosky C.W., 1978 - The family position of the peculiar genus Horaismoptera (Diptera: Tethinidae). Entomologica Germanica, 4(3/4): 327-336.

SASAKAWA M., 1986 - A revision of the Japanese Tethinidae (Diptera). Kontyû, 54(3): 433-441.

SASAKAwA M., 2014 - Family Canacidae. In, T. Nakamura, T. Saigusa and M. Suwa, editors, Catalogue of the Insects of Japan. Vol. 8 Diptera (Part 2, Brachicera Schizophora). Entomological Society of Japan, xiv +562 pp.

SÉGuy E., 1971 - Diptera. Pp. 344-348. In: VAn Zinderen Bakker E.M. van, Winterbottom J.M. And Dyer R.A. (eds), Marion and Prince Edward Islands. Report on the South African biological and geological expedition 1965-1966. Sponsored by the Department of Transport of the Republic of South Africa and supervised by the South African Scientific Committee for Antarctic Research. A.A. Balkema, Cape Town, xi+427 pp.

Strobl G., 1900 - Spanische Dipteren. Wiener Entomologische Zeitung, 19: 1-10.

StURTEVAnt A.H., 1923 - New species and notes on synonymy and distribution of Muscidae Acalypteratae (Diptera). American Museum Novitates, 76: 1-12.

UDVARDY M.D.F., 1975 - A classification of the biogeographical provinces of the world. IUCN Occasional Paper, Morges, Switzerland, 18: 1-48.

VAnschuytbroeck P., 1976 - 22. Fam. Tethinidae. In: La Faune Terrestre de l'Île de Sainte-Hélène, page 106. Annales, Musée Royal de L'Afrique Centrale, Tervuren, Belgique, series IN-8, Sciences Zoologiques No. 215.

Vockeroth J.R., 1987 - 101. Tethinidae. In: McAlPine J.F., ed., Manual of Nearctic Diptera, 2: 1073-1078. Ottawa: Research Branch, Agriculture Canada, Monograph 28, pages iv+675-1332.

Vockeroth J.R., 1995 - Validation of nomina nuda of Nearctic Tethinidae, Scathophagidae, and Muscidae proposed in Manual of Nearctic Diptera. Proceedings of the Entomological Society of Washington, 97(3): 732-734.

Williston S.W., 1893 - List of Diptera of the Death Valley Expedition. North American Fauna, 7: 253-259.

WiLliston S.W., 1896 - XI. On the Diptera of St. Vincent (West Indies). Transactions of the Entomological Society of London, 3: $253-446$.

WIRTH W.W., 1956 - Two new Neotropical species of surf flies of the genus Canace (Diptera, Canaceidae). Revista Brasileira Entomologica, 5: 161-165. 